\title{
Model Pertuturan Anak Down Syndrome SMA Luar Biasa Dian Grahita Jakarta: Kajian Pragmatik
}

\author{
Speech Model for Down Syndrome Children at Dian Grahita Special High School \\ Jakarta: Pragmatic Study
}

\author{
Wini Tarmini ${ }^{1, *}$, Abd. Rahman A. Ghani ${ }^{2}$, dan Martini Arelina Nike Pangaribuan ${ }^{3}$ \\ ${ }^{1,2,3}$ Universitas Muhammadiyah Prof. DR. HAMKA \\ ${ }^{1}$ Corresponding email: winitarmini@uhamka.ac.id \\ ${ }^{2}$ Email: rahman.ghani@uhamka.ac.id \\ ${ }^{3}$ Email: arelinanike@gmail.com
}

Received: 16 October 2020 Accepted: 4 May 2021 Published: 1 August 2021

\begin{abstract}
This study aimed to identify and describe the speech model for children with down syndrome in Dian Grahita Special High School Jakarta with a pragmatic study. This research is qualitative. The subjects in this study were Dian Grahita Special High School students in Central Jakarta. The results of the research include: (a) representative speech by stating, agreeing, mentioning, showing, admitting, reporting; (b) commissive speech to agree, threatening: (c) directive speech ordering, inviting, warning, requesting, ordering; (d) expressive speech to criticize, apologize, complaining, thanking; and (e) declarative speech to prohibit. According to Searle, this study found 55 groups of speech acts with 87 variants of speech acts from the five major groups of speech acts. The percentage of speech acts data for children with Down syndrome is as follows. Representative utterances are 54 utterances or equivalent to $62 \%$, commissive utterances are 4 utterances or equivalent to $5 \%$, directive utterances are 21 utterances or equivalent to $24 \%$, expressive utterances are 7 utterances or equivalent to $8 \%$, and declarative utterances are 1 utterance or the equivalent of 1\%. Students understand the communication conveyed by the teacher in classroom learning even though they express it only with short answers, including lingual markers, yes, no, okay, sorry, beware, already, not yet.
\end{abstract}

Keywords: children with down syndrome, Dian Grahita special high school, speech model

\begin{abstract}
Abstrak: Tujuan penelitian ini adalah untuk mengetahu dan mendeskripsikan model pertuturan anak down syndrome di SMA Luar Biasa Dian Grahita Jakarta dengan kajian pragmatik. Penelitian ini merupakan penelitian kualitatif. Subjek dalam penelitian ini adalah siswa SMA Luar Biasa Dian Grahita di Jakarta Pusat. Hasil penelitian model anak down syndrome di SMA Luar Biasa Dian Grahita Jakarta dengan kajian pragmatik meliputi: (a) tuturan representatif dengan menyatakan, menyetujui, menyebutkan, menunjukkan, mengakui, melaporkan; (b) tuturan komisif dengan maksud menyanggupi, mengancam: (c) tuturan direktif menyuruh, mengajak, memperingatkan, meminta, memerintah; (d) tuturan ekspresif dengan maksud mengkritik, meminta maaf, mengeluh, mengucapkan terima kasih; dan (e) tuturan deklaratif dengan maksud melarang. Penelitian ini ditemukan 55 kelompok tuturan dengan 87 varian tindak tutur dari lima kelompok besar tindak tutur menurut Searle. Persentase data tindak tutur berbahasa anak down syndrome sebagai berikut. Tuturan representatif berjumlah 54 tuturan atau setara dengan $62 \%$, tuturan komisif berjumlah 4 tuturan atau setara dengan $5 \%$, tuturan direktif berjumlah 21 tuturan atau setara dengan $24 \%$, tuturan ekspresif berjumlah 7 tuturan atau setara dengan $8 \%$, dan tuturan deklaratif berjumlah 1 tuturan atau setara dengan $1 \%$. Siswa memahami komunikasi yang disampaikan oleh guru dalam pembelajaran di kelas walau mengungkapkannya hanya dengan jawaban yang singkat di antaranya ditandai penanda lingual ya, jangan, oke, sori, awas, sudah, belum.

Kata kunci: anak down syndrome, SMA LB Dian Grahita, model pertuturan
\end{abstract}

To cite this article:

Tarmini, W., Ghani, A. R. A. \& Pangaribuan, M. A. N. (2021). Model Pertuturan Anak Down Syndrome SMA Luar Biasa Dian Grahita Jakarta: Kajian Pragmatik. Diglosia: Jurnal Kajian Bahasa, Sastra, dan Pengajarannya, 4(3), 247-258. https://doi.org/10.30872/diglosia.v4i3.127 


\section{A. PENDAHULUAN}

Peringatan Hari Down Syndrome Sedunia mengangkat tema meningkatkan kesadaran tentang terhadap anak-anak berkebutuhan khusus (Kustiani, 2021). Dari tema tersebut menunjukkan bahwa penyandang down syndrome mendapat perhatian khusus untuk memiliki kehidupan yang setara. Di dunia saat ini diperkirakan ada 3.000-5.000 anak terlahir sebagai penyandang down syndrome tiap tahun. Sementara di Indonesia diperkirakan ada sekitar 300.000 orang penyandang down syndrome. Siswa SMA menurut perkembangan kondisinya seharusnya bisa memahami sebuah komunikasi yang disampaikan dalam bentuk dialog yang panjang dan membutuhkan suatu diskusi yang panjang. Model tuturan anak SMA tentunya sudah jauh lebih baik dari anak SD maupun SMP. Namun, tidak demikian dengan siswa SMA Luar Biasa Dian Grahita yang menyandang down syndrome. Mereka memiliki keterbatasan karena secara fisiologis perkembangan mereka berbeda dengan siswa SMA umumnya. Bukan hanya kromosomnya yang berbeda tetapi juga fungsi otak kanan yang digunakan dalam mengungkapkan ujaran anak down syndrome SMA Dian Grahita berbeda dengan siswa SMA umumnya. Kemampunan berbahasa anak down syndrome mengalami keterlambatan. Anak down syndrome hanya bisa merespon secara singkat dan belum mampu merespons dalam suatu uraian yang panjang dan terstruktur (Marta, 2017; Sumarlan \& Pamungkas, 2014).

Anak down syndrome mengalami kesulitan untuk memahami maksud ujaran yang disampaikan orang lain dan untuk menyampaikan keinginan dengan baik. Karakteristik bahasa dan komunikasi individu down syndrom bersifat konsisten (Martin, Klusek, Estigarribia, \& Roberts, 2009). Hal ini tentunya dapat menghambat proses kegiatan belajar mengajar di kelas. Guru tidak dapat memahami keinginan-keinginan siswa dan siswa sulit menyampaikan maksud dan keinginannya. Padahal, pemahaman siswa terhadap tuturan yang disampaikan oleh guru sangatlah penting dalam kegiatan pembelajaran di kelas. Tujuan pembelajaran dapat tercapai apabila ada komunikasi yang baik antara guru dan siswa.

Untuk memahami tuturan pendek dan singkat yang diungkapkan oleh siswa down syndrome perlu dibantu oleh konteks atau peristiwa tuturnya. Dengan melibatkan konteks, tuturan anak down syndrome akan lebih mudah dipahami. Namun demikian, siswa down syndrome tidak pernah mempertimbang apa yang harus dikatakannya dan apa yang harus tidak dikatakannya. Pemahaman tentang konteks atau peristiwa tuturan yang melatarbelakanginya merupakan salah satu upaya untuk memahami maksud tuturan siswa down syndrome (Tarmini \& Safi'i, 2018). Oleh karena itu, tuturan anak down syndrome yang dikaitkan dengan konteks perlu dikaji secara mendalam. Penelitian yang terkait dengan tuturan anak down syndrome sudah pernah dilakukan oleh beberapa peneliti lain hanya saja penelitian tersebut menggunakan kajian dengan morfologi dan fonologi (Joko, 2019; Dewi, 2014).

Penelitian anak down syndrome yang dikaitkan dengan bidang pragmatik belum banyak dilakukan. Berdasarkan alasan itu, peneliti melakukan penelitian dengan berjudul Model Pertuturan Anak Down Syndrome SMA Luar Biasa Dian Grahita Jakarta: Kajian Pragmatik. Fokus penelitian adalah tuturan anak down syndrome di SMA Luar Biasa Dian Grahita Jakarta dalam pembelajaran di kelas. 
Tujuan penelitian ini adalah (1) untuk mengetahui dan mendeskripsikan tuturan siswa SMA Luar Biasa Diangrahita dan (2) untuk mendeskripsikan kemampuan siswa dalam memahami komunikasi yang disampaikan oleh guru dan mengetahui efektifitas pembelajaran di kelas. Penelitian ini menggunakan kajian di bidang pragmatik. Pemahaman makna dalam perspektif pragmatik dipengaruhi oleh ekspresi jarak relatif yang menyebabkan penutur mempertimbangkan apa yang dikatakan dan tidak dikatakannya. Pragmatik merupakan kajian makna penutur yang disesuaikan dengan konteksnya sehingga hal yang dikomunikasikan dimungkinkan lebih dipahami daripada hal yang dikatakan (Wijana \& Rohmadi, 2009).

Kajian pragmatik dapat memberikan keuntungan, yaitu dapat membicarakan makna yang dimaksudkan oleh orang-orang sesuai asumsi, maksud atau tujuan, dan jenis-jenis tindakan ketika bertutur (Mukhroji, Nurkamto, Subroto, \& Tarjana, 2019; Pijnacker, Hagoort, Buitelaar, Teunisse, $\&$ Geurts, 2009). Searle menggolongkan lima jenis tindak tutur, yaitu tindak tutur representatif, direktif, ekspresif, komisif, dan deklaratif. Kelima jenis tindak tutur tersebut dijadikan dasar untuk menganalisis data dalam penelitian ini (Ainin, Rokhmansyah, \& Purwanti, 2019; Tarmini, Safi'i, \& Solihati, 2020)

\section{B. METODE}

Penelitian ini menggunakan jenis penelitian deskriptif kulaitatif yang bertujuan mendeskripsikan atau menggambarkan fenomena-fenomena yang ada (Saputro, Tarmini, \& Hikmat, 2020). Secara sistematis, faktual, dan akurat mengenai data, sifat-sifat serta hubungan fenomena yang sedang diteliti sesuai dengan sifat alamiah data itu berupa tuturan anak down syndrome (Emzir, 2018). Sumber data dalam penelitian ini adalah tuturan anak down syndrome di SMA Luar Biasa Dian Grahita Jakarta tahun pelajaran 2019/2020 sebanyak 18 orang siswa. Jumlah siswa dari kelas 10 sebanyak 8 orang, dari kelas 11 sebanyak 3 orang, dan kelas 12 sebanyak 7 orang. siswa. Sumber data dijaring melalui rekaman saat siswa melakukan kegiatan pembelajaran di kelas. Pemeriksaan keabsahan data dalam penelitian ini dilakukan dengan uji kredibilitas data dan reliabilitas data melalui pengamatan, triangulasi dan FGD. Penelitian lapangan dilakukan untuk memperoleh data primer melalui perekaman data langsung saat kegiatan pembelajaran di kelas. Teknik analisis data dalam penelitian ini dilakukan dengan cara sebagai berikut. Pertama, mengklasifikasi data tuturan siswa down syndrome sesuai penggolongan jenis tindak tutur yang dikemukakan Searle. Kedua, menganalisis tuturan siswa down syndrome berdasarkan jenis tindak tutur dengan melibatkan konteks atau peristiwa tutur yang melatarbelakanginya.

\section{PEMBAHASAN}

Pemahaman makna dalam perspektif pragmatik dipengaruhi oleh ekspresi jarak relatif yang menyebabkan penutur mempertimbangkan apa yang dikatakan dan tidak dikatakannya. Namun tidak demikian halnya dalam tuturan siswa down syndrome, mereka mengungkapkan tuturannya terbatas dengan yang ada dalam pikirannya tanpa memikirkan lawan tuturnya bisa memahami atau tidak. Pragmatik merupakan kajian makna penutur yang disesuaikan dengan konteksnya sehingga hal yang dikomunikasikan dimungkinkan lebih dipahami daripada hal yang dikatakan. 
Dengan kajian pragmatik, model tuturan siswa down syndrome SMA Luar Biasa Dian Grahita dalam proses pembelajaran di kelas dapat dideskripsikan. Tuturan yang dimiliki anak down syndrome di SMA Luar Biasa Dian Grahita berdasarkan besarnya persentase Tuturan representatif berjumlah 54 tuturan atau setara dengan $62 \%$, tuturan komisif berjumlah 4 tuturan atau setara dengan 5\%, tuturan direktif berjumlah 21 tuturan atau setara dengan 24\%, tuturan ekspresif berjumlah 7 tuturan atau setara dengan $8 \%$, dan tuturan deklaratif berjumlah 1 tuturan atau setara dengan $1 \%$.

Tuturan yang mendominasi dalam tuturan anak down syndrome SMA Luar Biasa Dian Grahita adalah tuturan representatif. Penyebab tuturan representatif yang paling mendominasi dibandingkan dengan tuturan yang lain dapat dikemukakan bahwa siswa down syndrome kurang memilki kemampuan untuk memerintah; mengkritik, melarang. Siswa down syndrome lebih banyak menyatakan, menyetujui, menyebutkan, menunjukkan, dan mengakui yang masuk dalam jenis tuturan representatif dengan penanda lingual berupa kata-kata singkat dan pendek. Berikut ini adalah jenis tuturan siswa down syndrome saat pembelajaran di kelas.

\section{Tuturan Representatif}

Berdasarkan hasil analisis data, tuturan representatif anak down syndrome berjumlah 54 tuturan atau setara dengan 62\% merupakan tuturan yang kecenderungannya paling banyak muncul atau mendominasi tuturan siswa down syndrome. Data yang menunjukkan tuturan representatif dapat dilihat pada data [1], [2], [4], [5], dan [7].

[1] Guru : Praktek memasak bolu tape ya.

[Guru menggeser tepung, gula, dan Loyang kue ke dekatnya.

Siswa 1: Ya.

Siswa 2: Ya.

Guru : Bolu tape, ya. Bahannya sudah di sini, ya.

Siswa 1: Oke.

Siswa 2: Ya, ya.

[2] Guru : Ada tepung, gula.

[Saat guru bicara, siswa 1 memindahkan tepung ke depannya, siswa 2 menggeser Loyang ke dekatnya]

Siswa 3 : $\quad$ (siswa menunjuk gula dan menggeser kembali gula ke dekat gurunya) Gula.

Siswa 1: Gula.

Siswa 3: Palmia.

[4] Guru : (memegang margarin) Ini margarin (margarin yang dipegang merek palmia)

Beberapa siswa : Margarin.

Siswa 3 : Palmia.

Siswa lain : Ini kali.

Guru : Kalau palmia itu merek. Boleh simas, boleh margarin. 


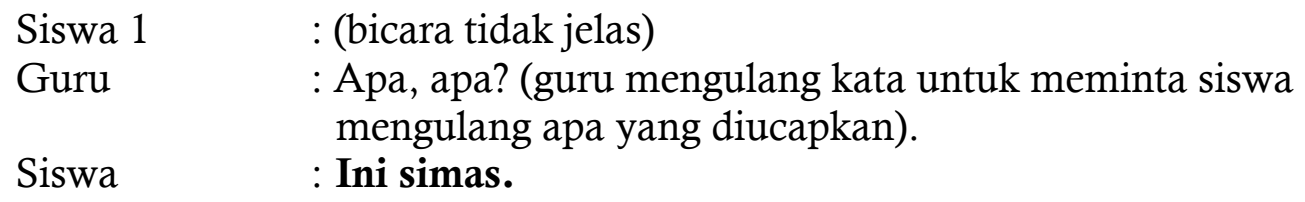

[5] Guru : Iya. sama, sama, cuma mereknya. (Guru mengambil plastik berisi bahan lainnya. Sambil membuka plastik)

Siswa 2: Oh (respons saat guru membuka plastik)

[7] Guru : Nanti dulu..bolu apa,Nak tadi? Tape..

Siswa : pe..

Siswa : Tape

Siswa : Bolu tape

Dalam contoh data [1], siswa 1 dan siswa 2 menyatakan maksud dengan tuturan representatif persetujuannya dalam pembelajaran membuat bolu tape yang ditandai dengan penanda lingual ya, oke, ya ya. Dalam contoh data [2], siswa menyatakan maksud dengan tuturan representatif menyebutkan bahan-bahan yang dipergunakan dalam pembelajaran ditandai dengan penanda gramatikal yang dilatarbelakangi oleh konteks atau peristiwa tutur. Dalam contoh data [4], siswa 3 menyatakan maksud dengan tuturan representatif menyebutkan bahan yang pegang oleh guru ditandai secara kontekstual. Siswa lain menyatakan dengan maksud tuturan representatif menunjukkan margarin dengan berbagai mark ditandai dengan penanda gramatikal ini. Dalam contoh data [7], siswa menyatakan maksud dengan tuturan representatif menyebutkan ulang dari apa yang disampaikan guru yang ditandai dengan penanda gramatikal pengulangan kata.

\section{Tuturan Komisif}

Berdasarkan hasil analisis data, tuturan komisif anak down syndrome berjumlah tuturan komisif berjumlah 4 tuturan atau setara dengan 5\%. Data yang menunjukkan tuturan komisif dapat dilihat pada contoh data [18], [31], [36], dan [54].

[18] Guru : Mantap. Taruh sana lagi (menunjuk kardus tempat telur, dan siswa menuruti). Pintar ya.

Siswa : Ada lagi, Bu?

Guru : Sudah?

Siswa : heeh..

Siswa 4 : Bu, susah, Bu. (berusaha membuka tepung terigu dengan gunting)

Guru : Susah? (sambil menghampiri siswa yang berusaha membuka tepung terigu dengan gunting) Begini, Tan.

Siswa 2 : Begini ni, Tan. (menegakkan plastik tepung terigu) Tuh....

[31] Guru: (siswa yang mencuci tangan sudah kembali kemudian guru menyerahkan baskom adonan kemudian mengajari siswa menuang adonan ke dalam loyang) pegangnya begini, Mas. 
dari sini (mengarahkan adonan ke loyang agar terlihat oleh teman-teman) gini lho..Nah..

Siswa : aku aja,Bu. Aku aja (Sambil memegang baskom adonan dan mulai dituangkan)

[36] Guru : Kus tidak Herbio terus. Wini gula pasirnya taruh di meja.

Siswa : Meja. (mengulang ucapan guru)

Siswa : Yang ini, Bu.

Guru : Iya..

Siswa : Angel.

Siswa : Minta tambah, Bu.

Guru : Iya. Sudah sana.

Siswa : Aku cuci piring, Bu.

Guru lain : Nanti, nanti.

[54] Guru : Hup.. (menanggapi pukulan yang diberikan masing-masing siswa)

Siswa : Tahu kan mati deh lo..

Dalam data [18] siswa menerapkan tuturan komisif kesanggupan melakukan yang diinstruksikan guru yaitu menaruh barang di kardus yang ditandai dengan penanda gramatikal heeh.., dan siswa tersebut pula memberikan penawaran bantuan. Dalam data [31] Siswa menerapkan tuturan komisif kesanggupan untuk melakukan aktivitas dari gurunya yang ditandai dengan penanda gramatikal $\boldsymbol{a} \boldsymbol{k} \boldsymbol{u}$ saja. Dalam data [36] Siswa menerapkan tuturan komisif kesanggupan melakukan kegiatan yang ditandai dengan penanda gramatikal Subjek + cuci piring. Siswa menerapkan tuturan direktif meminta yang ditandai dengan penanda gramatikal minta tambah. Dalam data [54] Siswa menerapkan tuturan komisif mengancam yang ditandai dengan penanda gramatikal tahukan mati deh lo.

\section{Tuturan Direktif}

Berdasarkan hasil analisis data, tuturan Direktif anak down syndrome berjumlah berjumlah 21 tuturan atau setara dengan 24\%, Data yang menunjukkan tuturan komisif dapat dilihat pada contoh data [11], [14], [15], [20], dan [26].

[11] Guru : Bawa sono dulu. Hati-hati.

Siswa 4 : (celetuk) Apa, pesek. He he.

Siswa 1 : Shh.. (ke arah temannya)

Siswa 3 : (mendatangi meja membawa mangkok 3 buah)

Siswa 4 : Sini, sini (langsung mengambil mangkok dari siswa 3 kemudian mengeluarkan mangkok dari susunannya. Siswa 2 tadinya ingin mengambil)

[14] Guru : Dihitung ya, Ju. (Siswa 4 mengambil gunting yang ada dekat guru)

Guru : Margarinnya mana margarin? Siapkan.

Siswa 2 : Pinjam (ke arah siswa 4 mengambil gunting) 
Guru : Gini ya, Anak-anak. (mengambil margarain disiapkan untuk digunting) Ya. Digunting

[15] Guru : Yang banyak, Rikikus.. (Siswa mengeluarkan kembali tape yang ada dalam plastic ke ulekan)

Siswa 4 : Bu, Bu..sini, Bu.. (sambal menunjuk sesuatu ke guru dan menunjuk tepung terigu yang ada di depannya)

Guru : apa? Oh ini..gunting. nih..gunting. Jangan berantakan ya..

[20] Siswa 4 : Gula.. (temannya menggeserkan gula ke arah siswa 4)

Guru : Satu lima nol ya, Tan. (Guru mengapresiasi aktivitas siswa lain yang mengulek tape). Bagus, Kus. Mantap (siswa 4 menyendokkan gula ke mangkuk ukur)

Siswa 1 : Bu, ayo, Bu.

Guru : Iya. Nanti dulu. Disiapkan bahan-bahannya.(berjalan menuju ke siswa 1)

Siswa 1 : (menyapa guru lain yang ada di dekat situ) Hai, Bu. Bu..

Guru lain : shht.. (siswa langsung diam)

Guru : Sekarang ini belajar memasak ya.

Siswa : Ini harus didiemin.

Siswa lain : Iya, iya.

Guru : Kita siapkan dulu gulanya

[26] Siswa 4 : (saat guru sedang menjelaskan langkah-langkah membuat adonan bolu ada siswa lain yang menaggapi kegiatan temannya menuangkan mentega cair)

Stop. Udah ni, Sop. (suara agak tidak jelas dari siswa yang mengamati)

Siswa 1 : Udah ni stop ntar ini. (siswa yang menuangkan mentega bersama siswa)

Dalam data [11] Siswa menerapkan tuturan direktif 4 mengajak temantemannya yang ditandai dengan penanda gramatikal sini. Dalam data [14] Siswa 2 menerapkan tuturan direktif meminta kepada siswa 4 gunting yang ditandai dengan penanda gramatika pinjam. Dalam data [15] Siswa 4 menerapkan tuturan direktif mengajak gurunya untuk membersamainya yang ditandai dengan penanda gramatikal sini. Dalam data [20] Siswa 4 menerapkan tuturan direktif memerintah untuk mengambilkan gula yang ditandai dengan penanda gramatikal gula, dan tuturan direktif mengajak gurunya untuk membersamainya yang ditandai dengan penanda gramatikal ayo. Dalam data [26] Siswa 4 dan siswa 1 menerapkan tuturan direktif memerintah untuk menghentikan temannya menuang mentega cair yang ditandai dengan penanda gramatikal stop.

\section{Tuturan Ekspresif}

Berdasarkan hasil analisis data, tuturan ekspresif anak down syndrome berjumlah 7 tuturan atau setara dengan 8\%. Data yang menunjukkan tuturan komisif dapat dilihat pada contoh data [12], [30], [37], [44], dan [46]. 
[12] Siswa 4 : Sini mau nimbang.

Siswa : (mengulurkan tangan kepada siswa 4) Sori, Chang..

Siswa 1 : Chang, sori.. (bicara kepada siswa 4 agar menerima uluran tangan siswa 2 kemudian siswa 4 menjabat tangan siswa 2) Guru mendatangi meja siswa lalu mengulang kata bolu tape dan siswa-siswa lain menyebut tape.

Siswa : Ni, Hong. Ajun belum.

Siswa : Ni, ni, tepung.

[30] Guru : Ya. Gini. nanti dulu bukan begitu (siswa mengangkat adonan ditahan oleh guru kemudian berpindah ke depan adonan, siswa yang mengaduk adonan meninggalkan adonan untuk mencuci tangannya)

Siswa : Ed, good did your help.

Guru lain : Bu Pur kompornya berapa banyak? Semua?

Guru : Ya. Semua. (Guru menanggapi guru lain sambil merapikan adoanan di baskom kemudian menggeser loyang yang ada di meja)

[37] Guru : Ntar saya yang lap ya. Ini, Win taruh di tempat cuci.

Siswa wanita : Taruh di tempatnya.

Siswa : Tempat cuci numpang lewat.

Siswa : $\mathrm{Bu}$, lihat.

Siswa : Alah etamon.. Baik, etamon baik.

[44] Siswa : Olahraga? (bertanya ke guru sambil menunjuk bola yang akan dipukul ke arah lawan main)

Guru : Yup. Hei.., yup.., mantap, Le... (menanggapi siswa yang bermain)

Guru lain : Ayo John.. Kejar..

Guru : John... Le...

Siswa : Aha... (saat bola tidak berhasil ditepak balik oleh salah satu temannya)

[46] Guru : Ari.. (memanggil siswa berikutnya, siswa maju) Ayo, Mas Ari..

Guru lain : Jangan salah pukul ya, Le.

Guru : : Ayo, Le. Kejar, ya, Ri. Mantap. Hup.

Siswa : Bagus (menanggapi temannya yang berhasil membalas tepakan bola dari lawan)

Guru : Kejar... bagus.

Dalam data [12] Siswa 1 menyampaikan tuturan ekspresif permintaan maaf yang ditandai dengan penanda gramatikal maaf. Dalam data [30] Siswa menerapkan tuturan ekspresif terima kasih dari apa yang telah diarahakn oleh gurunya yang ditandai dengan penanda gramatikal good did your help. Dalam data 
[37] Siswa wanita menerapkan tuturan ekspresif ditandai dengan pernyataan Alah etamon..baik, etamon baik. Dalam data [44] Siswa lain menerapkan tuturan ekspresif memuji keberhasilan diri sendiri dengan penanda gramatikal aha... Dalam data [46] Siswa menerapkan tuturan ekspresif memuji keberhasilan temannya dengan penanda gramatikal bagus.

\section{Tuturan Deklaratif}

Berdasarkan hasil analisis data, tuturan deklaratif anak down syndrome berjumlah 1 tuturan atau setara dengan 1\%. Data yang menunjukkan tuturan deklaratif dapat dilihat pada contoh data [27].

[27] Guru : (kepada siswa yang menuangkan mentega cair) Bawa ke tempat cucian lah.. Aduk yang merata.

Siswa lain : Dicampur, ya.

Siswa lain : Eh, campur, campur, campur.

Guru : Terus.

Siswa lain : Tuh campur, ya, campur.

Siswa wanita : Jangan pakai tangan.

Siswa : Yah.

(sambil menunjuk adonan yang kena ke jarinya lalu dijilat, siswa lain menyanyikan lagu selamat ulang tahun kami ucapkan kemudian lagu berhenti)

Dalam data [27] Siswa wanita menerapkan tuturan deklaratif melarang yang ditandai dengan penanda lingual jangan.

Berdasarkan hasil pembahasan dapat dikemukakan bahwa Siswa Down Syndrome memahami komunikasi yang disampaikan oleh guru dalam pembelajaran di kelas. Pemahaman komunikasi antara siswa down syndrome dengan guru dalam pembelajaran di kelas dapat dijelaskan oleh peristiwa tutur yang terjadi saat itu. Selain dijelaskan oleh peristiwa tutur, adanya pemahaman dalam komunikasi tersebut dibuktikan oleh adanya respon siswa down syndrome terhadap pertanyaan guru dalam proses pembelajaran di kelas. Hal ini dapat dibuktikan dari adanya respon siswa down syndrome walau responnya tersebut hanya berupa kalimat singkat atau kalimat tidak lengkap dengan kata-kata pendek yang terdiri atas satu kata atau dua kata saja. Kata yang digunakan berupa penanda lingual ya, oke, jangan, sori, awas, sudah, belum. Untuk lebih jelasnya dapat dilihat pada tabel 1 model tuturan siswa down sydrome dan gambar 1 persentase tuturan anak down syndrome. 
Tabel 1. Model Tuturan Anak Down Syndrome

\begin{tabular}{|c|c|c|c|}
\hline No & Tuturan & Maksud Tuturan & Penanda Lingual \\
\hline \multirow[t]{8}{*}{1} & Representatif & menyatakan & $\mathrm{Ya}$ \\
\hline & & menyetujui & Oke \\
\hline & & menyebutkan menunjukkan & Nah ok \\
\hline & & mengakui & Ini kali \\
\hline & & melaporkan & Belum \\
\hline & & & Begini nih \\
\hline & & & $\mathrm{Nih}$ \\
\hline & & & $\mathrm{Tu}, \mathrm{tu}, \mathrm{tu}$ \\
\hline \multirow[t]{4}{*}{2} & Komisif & menyanggupi & Heeh \\
\hline & & mengancam & Aku aja \\
\hline & & & Aku cari \\
\hline & & & Tahu kan mati deh lo \\
\hline \multirow[t]{8}{*}{3} & Direktif & menyuruh & Nih baca \\
\hline & & mengajak & Ya, lanjut \\
\hline & & memperingatkan & Sini \\
\hline & & meminta & Ayo \\
\hline & & memerintah & Stop \\
\hline & & & Awas tumpah \\
\hline & & & Minta bu \\
\hline & & & Lewat sana \\
\hline \multirow[t]{3}{*}{4} & Ekspresif & $\begin{array}{l}\text { mengkritik, meminta maaf, } \\
\text { mengeluh }\end{array}$ & Laper ya \\
\hline & & mengucapkan terima kasih & Terima kasih \\
\hline & & & $\begin{array}{l}\text { Baik } \\
\text { ahaaa }\end{array}$ \\
\hline 5 & Deklaratif & melarang & jangan \\
\hline
\end{tabular}

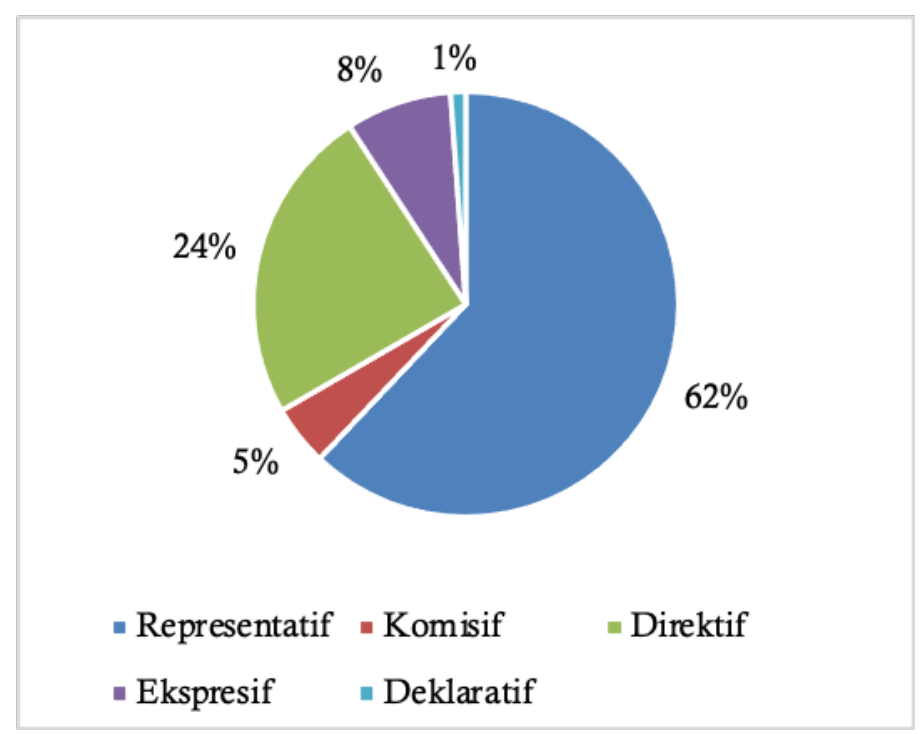

Gambar 1. Persentase Tuturan Siswa Down Syndrome

Berdasarkan paparan di atas diperoleh tuturan yang dimiliki anak down syndrome di SMA Luar Biasa Dian Grahita secara berdasarkan persentasenya jenis tuturan representatif paling mendominasi penggunaannya, yaitu sebanyak $62 \%$. Dan tuturan deklaratif yang paling minim, yaitu sebanyak 1\%. Penyebab tuturan 
representatif yang paling mendominasi dibandingkan dengan tuturan yang lain dapat dibuktikan bahwa anak down syndrome kurang memiliki kemampuan untuk memerintah (dalam tuturan direktif); mengkritik (tuturan ekspresif); melarang (tuturan deklaratif). Anak down syndrome lebih banyak menyatakan, menyetujui, menyebutkan, menunjukkan, dan mengakui yang masuk dalam jenis tuturan representatif dengan penanda lingual berupa kalimat singkat atau kalimat tidak lengkap pendek.

\section{PENUTUP}

Berdasarkan hasil penelitian dan pembahasan yang telah diuraikan pada bagian sebelumnya dapat disimpulkan sebagai berikut. Pertama, model pertuturan anak down syndrome SMA Luar Biasa Dian Grahita Jakarta dalam kajian pragmatik meliputi (a) pertuturan representatif dengan maksud menyatakan, menyetujui, menyebutkan, menunjukkan, mengakui, melaporkan; (b) pertuturan komisif dengan maksud menyanggupi, mengancam: (c) pertuturan direktif dengan maksud menyuruh, mengajak, memperingatkan, meminta, memerintah; (d) pertuturan ekspresif dengan maksud mengkritik, meminta maaf, mengeluh, mengucapkan terima kasih; dan (e) pertuturan deklaratif dengan maksud melarang. Penelitian menghasilkan 55 kelompok tuturan dengan 87 varian tindak tutur dari lima kelompok besar tindak tutur menurut Searle. Persentase data tindak tutur berbahasa anak down syndrome sebagai berikut. Tuturan representatif berjumlah 54 tuturan atau setara dengan $62 \%$, tuturan komisif berjumlah 4 tuturan atau setara dengan $5 \%$, tuturan direktif berjumlah 21 tuturan atau setara dengan 24\%, tuturan ekspresif berjumlah 7 tuturan atau setara dengan $8 \%$, dan tuturan deklaratif berjumlah 1 tuturan atau setara dengan $1 \%$. Kedua, siswa down syndrome memahami komunikasi yang disampaikan oleh guru dalam pembelajaran di kelas walau mengungkapkannya hanya dengan jawaban yang singkat ditandai penanda lingual ya, jangan, oke, sori, awas, sudah, belum.

\section{DAFTAR PUSTAKA}

Ainin, N., Rokhmansyah, A., \& Purwanti. (2019). Tipe Tuturan Remaja Perempuan Yatim dalam Interaksi Sehari-Hari: Kajian Pragmatik. DIGLOSIA: Jurnal Kajian Bahasa, Sastra, Dan Pengajarannya, 2(1), 1-14.

Dewi, Y. F. (2014). Kemampuan Morfologis pada Tuturan Anak Down Syndrome yang Tergolong Mampu Latih. Universitas Pendidikan Indonesia.

Emzir. (2018). Metodelogi Penelitian Kualitatif Analisis Data. Depok: Rajawali Press.

Joko, P. (2019). Gangguan Fonologis Anak Penyangdang Down Syndrome Berdasarkan Tingkat Intelegensi: Sudi Kasus pada D.A. dan M.A.S di Panti Sosial Bina Grahita Padang. Universitas Andalas.

Kustiani, R. (2021). Presiden Erdogan: Penyandang Down Syndrome Memperkaya dan Bikin Indah Dunia. Tempo.Co.

Marta, R. (2017). Penanganan Kognitif Down Syndrome melalui Metode Puzzle pada Anak Usia Dini. Jurnal Obsesi : Jurnal Pendidikan Anak Usia Dini, 1(1), 32. https://doi.org/10.31004/obsesi.v1i1.29

Martin, G. E., Klusek, J., Estigarribia, B., \& Roberts, J. E. (2009). Language Characteristics of Individuals with Down Syndrome. NIH Public Access, 29(2), 112-132. https://doi.org/10.1097/TLD.0b013e3181a71fe1

Mukhroji, M., Nurkamto, J., Subroto, H. D. E., \& Tarjana, S. S. (2019). Pragmatic 
forces in the speech acts of EFL speakers at Kampung inggris, Indonesia. Journal of Social Studies Education Research, 10(1), 38-60.

Pijnacker, J., Hagoort, P., Buitelaar, J., Teunisse, J. P., \& Geurts, B. (2009). Pragmatic inferences in high-functioning adults with autism and Asperger syndrome. Journal of Autism and Developmental Disorders, 39(4), 607-618. https://doi.org/10.1007/s10803-008-0661-8

Saputro, M. Y., Tarmini, W., \& Hikmat, A. (2020). Model Kesantunan Berbahasa Siswa Tionghoa Di Sekolah Pah Tsung Jakarta: Kajian Etnografi Komunikasi. Widyaparwa, 48(2), 148-160. https://doi.org/10.26499/wdprw.v48i2.646

Sumarlan, \& Pamungkas, S. (2014). Karakteristik Bahasa Anak-Anak Down Syndrome di Kampung Down Syndrome Kabupaten Ponorogo dalam "Languang Maintenave and Shidt" IV. Prosiding Eprins Undip, 72-77.

Tarmini, W., \& Safi'i, I. (2018). Kesantunan Berbahasa Civitas Academica Uhamka : Kajian Sosio-Pragmatik. Imajeri, 01(1), 77-91.

Tarmini, W., Safi'i, I., \& Solihati, N. (2020). Model Pertuturan Politikus Dalam Pemilu Di Indonesia : Kajian Sosiopragmatik. Metalingua, 18(2), 285-294.

Wijana, I. D. P., \& Rohmadi, M. (2009). Analisis Wacana Pragmatik: Kajian Teori dan Analisis. Surakarta: Yuma Pustaka. 